\title{
Differentiation and differences: anthropological research on the social integration of the Chaoxian immigrants currently residing in South Korea
}

Open Access

\author{
Weihua $\mathrm{Ma}^{1}$ (1) $\cdot \mathrm{Ji}^{\mathrm{Ch}} \mathrm{n}^{2}$
}

Received: 16 December 2020 / Accepted: 8 October 2021 / Published online: 30 October 2021

(c) The Author(s) 2021

\begin{abstract}
The occupational differentiation of the Chaoxian people (Korean Ethnic Group of China or Ethnically Korean Chinese Citizens) migrating to South Korea is an important factor leading to big differences in the social integration within this group. The marginalized characteristics of non-college educated immigrant workers in economic integration have caused them to experience difficulty in social interaction and cultural integration; the successful integration of the middle-and-high-end professional groups into South Korean society has promoted deep interaction and cultural homogeneity with South Koreans. Studying these differentiation and differences in the integration of Chaoxian immigrants into Korean society can not only show the diversity and complexity of cross-border ethnic issues. It is hoped that it will also have a certain positive guiding significance on the rational cross-border transnational migration of Chaoxian people.
\end{abstract}

Keywords Chaoxian people $\cdot$ Immigrants $\cdot$ Social integration · Differentiation ·

Difference $\cdot$ Cross-border ethnic group

Weihua Ma

ma-wh@126.com

Ji Chen

nkchenji@126.com

1 The Department of Sociology, Zhou Enlai School of Government, Nankai University, Tianjin, China

2 The Department of Political Science, Zhou Enlai School of Government, Nankai University, Tianjin, China 


\section{Introduction}

Social integration refers to the continuous social interaction process between relatively disadvantaged subjects and individuals or groups in specific communities at different levels of society (Chengwen and Jiayue 2012). The research on the social integration of international immigrants in Western academic circles, on the one hand, has constructed theories such as "cultural assimilation theory," "cultural shock theory" and "cultural assimilation model" based on the differences between immigrant culture and mainstream culture. The research presumes that immigrants adopt a single line of acceptance into the local mainstream culture. On the other hand, it reveals the integration, assimilation, separation, marginalization and other cultural adaptation strategies adopted by the immigrants trying to integrate into the mainstream society (Berry 2005; Berry 1997). It also shows the immigration policies of Western countries in different periods, such as multiculturalism, melting pot, isolation, exclusion and so on (Berry 2002). Some scholars believe that immigrants in different professions do not adopt the same adaptation strategies, that is, they show dynamic and spontaneous adaptation characteristics in different scenarios.

On this basis, Western scholars also discussed issues like the stages, goals, channels, and mechanisms of immigrants' integration into mainstream society. These theories emphasize the degree of cultural adaptation of immigrants and explain the process and status of the social integration of international immigrants in different countries, ethnicities and religions.

In the 1980s, Professor Chen Yongling of Minzu University of China first clearly put forward the concept of cross-border ethnic groups and related theories. At present, there is still no unified understanding of the definition of crossborder ethnic groups in China's academic circles, as researchers have explained it from different angles. Among them, there is a view that cross-border ethnic groups are formed in the process of historical development and live in two or more modern countries (ChunZi and Jianmin 1984). Since then, there have been many Chinese researchers and research results on ethnic groups living across national boundaries. Through field work on cross-border ethnic groups, such as the Kazakh, Tajik, Uzbek in the Xinjiang Uygur Autonomous Region, Miao, Dai people, Jingpo and other ethnic groups in Yunnan Province, domestic scholars have studied the meaning, formation, types, identity and practical significance of the cross-border ethnic groups and formed a cultural analysis perspective of "peaceful cross-border-living" (Manli 1995). The original purpose of the "peaceful cross-border-living" proposal was to explore similar historical and cultural traditions as well as common blood ties among cross-border ethnic groups from the perspective of the national security of surrounding areas, as well as its significance to the development of ethnic relations in neighbouring countries. Later, some researchers expanded its connotation and believed that "peaceful cross-border living" can also explain that after cross-border ethnic 
groups have experienced cross-border migration and returned to their ancestral home country, based on similar "cultural norms" (Jianxin 2008), social and cultural integration can be achieved and social assimilation can be successfully completed in the receiving country.

It should be emphasized that the western theories of social integration of immigrants are based on international immigrants with large cultural differences. Because the Chaoxian people (Korean Ethnic Group of China or Ethnically Korean Chinese Citizens) have some cultural similarities with the South Korean residents, it is difficult to concretely explain the integration of Chaoxian immigrants into South Korean society and the deep mechanism behind it using the views of assimilation, separation, exclusion, and pluralism proposed by the Western theory of social integration of immigrants. Based on the angle of analysis of "peaceful cross-residence" formed by cross-border ethnic research cases in Xinjiang, Yunnan and other places, it highlights the positive role of similar cultural characteristics and cultural memory in the integration of cross-border ethnic society. The question is whether the analytical perspective of "peaceful cross-living" can be applied to the unique situation of the integration of the Chaoxian immigrants into the South Korean society and whether it can explain many differences in social integration of cross-border ethnic groups.

The current research on the social integration of Chaoxian people (Korean Ethnic Group of China or Ethnically Korean Chinese Citizens) in South Korea mainly discusses the influencing factors affecting the group and the practical difficulties of this group's social integration. Some studies believe that the rising housing prices and children's schooling difficulties brought about by urban development in South Korea have become the main factors affecting the integration of Chaoxian immigrants into the South Korean society (Mu-Seon 2017). Although the Chaoxian people have an identity with Korean language, history, culture, etc., they still can't get rid of the "sense of destiny" brought on by their nationality differences in their social integration (Jeong-Eun 2018). Most Chaoxian immigrants believe that they are treated differently and that South Koreans do not treat them equally as members of society. This makes it difficult for them to integrate into the Korean society (Seung-Yeon 1994). There are also some studies that did not specifically discuss the social integration of the Chaoxian immigrants in South Korea, but incited relevant thinking when exploring cultural adaptation. For instance, some researchers believe that the Chaoxian immigrants in South Korea adapt to Korean cultures selectively and lack enthusiasm and initiative when it comes to deep integration (Meihua and Yue 2016). These studies analyzed the influencing factors and related dilemmas of the social integration of the Chaoxian immigrants in South Korea from the economic, social, and cultural levels, but paid little attention to the specific state of social integration. Many researchers regard the Chaoxian immigrants in South Korea as an "iron plate" and lack detailed classification in their research. They generally believe that Chaoxian immigrants' employment categories are single and that 
their social integration is difficult. In fact, the professional differentiation ${ }^{1}$ under the influence of visa types has created a clear socio-economic gap within the Chaoxian immigrants in South Korea, leading to different states of life when they integrate into South Korean society. The research on the social integration of Chaoxian immigrants in South Korea should be based on the existing research's foundation, and a necessity to pay more attention to the differentiation within the group and the heterogeneity of social integration on the basis of indepth fieldwork, and to highlight the diversity and differences in the integration of Chaoxian immigrants into the Korean society.

Since the establishment of diplomatic relations between China and South Korea in 1992, the South Korean government has formulated immigration policies to attract Chaoxian immigrants to work in South Korea in order to meet the labor demand for domestic economic development. According to relevant statistics, the total number of Chaoxian immigrants in South Korea at the end of 2016 was 626,655, of which 268,123 were visitor employment visa holders $(\mathrm{H}-2)$ and $241,056^{2}$ were foreign compatriot visa holders (F-4) (Ministry of Justice of Korea 2017). H-2 is referred to as the "visiting employment" group. From 2012 to 2016, the number of Chaoxian immigrants who went to South Korea through visiting employment remained at $303,000^{3}$ (Ministry of Justice of Korean 2012-2016), becoming the largest group of Chaoxian immigrants in South Korea. F-4 is known as the "foreign compatriots" group. Obtaining this visa generally requires more than 2 years of work experience after graduating from university, or possessing certain professional and technical qualifications, economic conditions, academic diplomas, and etc.. An F-5 visa is a Chaoxian immigrant with permanent residency qualification and is not restricted by types of employment. It is also called a "permanent residence" group. F-2 s are the spouses of those who have obtained permanent residency status, or the spouses of those who have obtained permanent residence qualification, and some people with refugee status. F-1 s are those who need to support children after they are married to a South Korean or need to support both parents and other family members, and are recognized by the local legal department to be eligible to stay and engage in related work (Ji and Nanri 2018). The five types of visas of Chaoxian immigrants in South Korea impact their occupational differentiation and are an important indicator of individual economic income and social status. This has become an important factor that results in differences when they integrate into South Korean society.

\footnotetext{
${ }^{1}$ The occupational differentiation of the Chaoxian immigrants in South Korea is influenced by a variety of factors including types of visas. According to the relevant laws of the Ministry of Law of South Korea, the visa types of the Chaoxian immigrants in South Korea are closely related to the types of occupations they are engaged in, i.e. a certain type of visa is often limited to a specific area of employment. For example, the scope of employment of $\mathrm{H}-2$ visa holders is mainly in the service sector, processing manufacturing, agriculture, forestry, fisheries and other types of employment. In actuality, some Chaoxian immigrants in South Korea do not necessarily work in visa-limited industries, although this is relatively rare.

${ }^{2}$ Ministry of Justice of Korea: "2016 Annual Report on Entry and Exit Statistics". 2016. https://www. immigration.go.kr/HP/TIMM/index.do?strOrgGbnCd=104000. Accessed 20 June 2017.

3 "Annual Report on Entry and Exit Statistics of Foreigners from 2012 to 2016" issued by the Ministry of Justice of Korea.2016. https://www.immigration.go.kr/HP/TIMM/index.do?strOrgGbnCd=104000. Accessed 30 January 2017.
} 


\section{Research methods}

\section{Research aims and significance}

In order to reveal the impact of the professional differentiation of Chaoxian people in South Korea and the status of different professional groups in the process of social integration, this article divides the Chaoxian immigrants in South Korea into the ordinary labor group (H-2s, F-2 s, F-1 s, and most F-4s) and the middle-and-high-end professional group (a small part of F-4s and F-5s), and expounds upon their differences in social integration from three aspects: economy, social relations, and culture.

\section{Research design}

From January to February 2017, the research team sorted out relevant literature. From March to June, the research team selected Yeongdeungpo District, Guro District, Geumcheon District of Seoul City, Ansan City and Suwon City of Gyeonggido and other places to conduct fieldwork.

\section{Participants}

During the fieldwork, the research team divided the subjects according to the types of visas and the proportion of Chaoxian immigrants in South Korea. Among these visa-type employees, the author conducted in-depth interviews with 51 Chaoxian immigrants in different occupations. In places such as enterprises, construction sites, schools, associations, hospitals, restaurants, shops, vegetable markets, churches, the author understands their basic economics, social contacts, cultural life and other basic conditions through participation and observation. From July to August of the same year, the author compiled the interview data and prepared for follow-up research and paper writing.

\section{Results}

The author had a profound understanding of the issues of professional Chinese Chaoxian immigrant groups holding different visas in South Korea such as the income level, social interaction, and cultural adaptation, on the basis of the application of participant observation and in-depth interview.

In particular, in-depth interviews with the group of the ordinary Chaoxian immigrant workers and the middle-and-high-end professional group of Chaoxian immigrants in South Korea show obvious differences in the level of their integration into Korean economy, society and culture, which contain deeper social and cultural connotation. They are manifested in two different states: the marginal and the mainstream. The "marginal" mainly is reflected in the high dependence of the group of the ordinary Chaoxian immigrant workers on the Chaoxian immigrant 
settlement areas, and in the fact that the majority of these ordinary immigrant workers are employed in low-end industries in South Korean, while the "mainstream" is reflected in the fact that most middle-and-high-end professionals have entered highlevel industries in South Korean. The two groups make sharp contrast.

There is a big difference between the ordinary immigrant workers and the middle-and-high-end professional groups in terms of social integration. On the one hand, the former is mainly active in the settlement areas and is limited to the social network within the group to form intra-ethnic social interaction, so it is relatively closed in terms of social integration with South Koreans. However, based on the characteristics of their work, a small number of F-4 and most F-5 visa holders in the middle-and-high-end professional groups interact with South Koreans through professional contacts and public activities of their communities outside the ethnic group and community public activities. Therefore, their social interactions are deeper.

As a cross-border ethnic group, there are similarities in the cultural origin between the Chaoxian immigrants and the Koreans. Therefore, there are differences between the Chaoxian immigrants in South Korea and the other international immigrants in general. For example, the Chaoxian people and Koreans share some similarities in language, culture and psychology, as well as cultural differences in recent decades caused by the different development trajectories of China and South Korea. The Chaoxian immigrants in South Korea reflect differences in the process of integrating into the mainstream South Korean culture on the basis of their internal differences in education, occupation and income. The middle-and-high-end professional group is easier to integrate into Korean mainstream culture, such as clothing, temperament and consumption, while the ordinary labor group shows more obvious cultural differences with Korean mainstream in terms of clothing, accent, temperament and consumption.

Therefore, the ordinary Chaoxian immigrant worker group is quite different from South Koreans in daily life and values. They have to learn the daily life style and values and strive to adapt to South Korean culture; while the middle-and-high-end professional group has a similarity with South Koreans in religious culture, behavior patterns and other aspects, which makes them integrate better into South Korean culture with fewer obstacles in cultural integration.

\section{Findings and discussion}

\section{The marginal and the mainstream: group differences in the economic integration of Chaoxian immigrants in South Korea}

\section{Low-end service work leads to marginalization of the economic integration of the ordinary Chaoxian immigrant workers}

The ordinary migrant workers of Chaoxian immigrants in South Korea live in areas where labor is most needed in the economic developed cities such as Seoul, Ansan of Gyeonggi-do, and Suwon. These areas have convenient transportation and large labor-intensive economies, which can provide a large number of jobs. The 
investigation found that about a quarter of the Chaoxian immigrants lived here. After years of development, Seoul and its surrounding areas have formed several largescale Chaoxian settlement areas. The first settlement area is in Daelim 1 Dong, Daelim 2 Dong, and Daelim 3 Dong in Yeongdeungpo District in Seoul, with approximately 36,000 Chaoxian immigrants. The second settlement area is in Garibong Dong, Guro 2 Dong, and Guro 4 Dong in Guro District in Seoul, with approximately 27,000 Chaoxian immigrants. The third settlement area is in Gasan-Dong, Doksan 3 Dong, and Doksan 1 Dong in Geumcheon District in Seoul, with approximately 19,000 Chaoxian immigrants. The fourth settlement area is in Wongok-Dong, XinjiDong, and Jungang-Dong in Tanyuan District in Anshan City of Gyeonggi-do, with approximately 38,000 Chaoxian immigrants. Most of them have relations with relatives, friends, and fellow villagers, while some South Koreans also live in the settlements. Some H-2 and F-4 visa holders engage in various occupations in these communities, forming working environments that use settlement area as the main place of livelihood. While some of the immigrant workers living in the settlement area are working in this manner, others are providing labor for small and medium-sized South Korean enterprises and related social service industries.

There are various industries including large and small vegetable markets, restaurants, supermarkets, hotels, electronic products, clothing, toys, luggage, accessories, department stores, hardware materials, transportation, logistics, food processing and many others in the settlement area. There are more than 340 stores in Daelim-Dong, Yeongdeungpo-gu District in Seoul, over 260 in Garibong-Dong Guro-gu District in Seoul, and at least 90 stores in other settlements. This situation makes it easy for Chaoxian immigrant workers to live in these settlements to obtain employment opportunities. It also guarantees fulfillment of their survival needs, avoids the situation of local detention or being forced to return home due to their inability to integrate into the South Korean economy in a timely manner. Most of the industries in the settlement areas mainly serve Chaoxian immigrants and have characteristics of "self-sufficiency." A small number of Chaoxian immigrants who are flexible and good at doing business, stand out in this economic model, rising from relatively low-level immigrant workers to the upper-middle class of Chaoxian immigrants in South Korea. However, economic activities that depend on settlements for a living are likely to form a closed compartment, which weakens Chaoxian immigrants's initiative and enthusiasm to further integrate into the mainstream economy of South Korea. These Chaoxian immigrants in South Korea rely more on the living environment. Once they leave the settlement area, they often become unable to adapt to the external environment. It is difficult for them to find a job to meet basic survival needs outside the settlement area.

Due to the limitation of their education and professional skills, the ordinary Chaoxian immigrant workers outside their settlements are excluded from work in the fiercely competitive job market. They can only make a living in the small-andmedium-sized South Korean enterprises with low-income and the service industry with low requirements for knowledge and technology. Their wages are settled on a daily basis, and their income is low and unstable. Most of these people are frugal and remit the money they have saved to Yanbian Korean Autonomous Prefecture (hereinafter referred to as "Yanbian"), Jilin Province, China and other places. 
Many money exchange offices have been opened on the streets of Daelim-Dong and Myeong Dong in Seoul, mainly engaged in the business of exchanging Renminbi and US Dollars into Korean Won or vice versa. The Industrial and Commercial Bank of China opened a branch in Daelim-Dong to facilitate the exchange of Korean Won to Renminbi and the transfer to Chinese family members. When a certain amount of wages has been accumulated, many ordinary Chaoxian immigrant workers in South Korea remit money to their Chinese family members through various channels. During the fieldwork, the author often heard complaints and grievances about income from some Chaoxian immigrant workers at the bottom:

We can't find good jobs. They are left to the locals. When we look for a job, the locals won't act in our favor. The South Koreans have good jobs. South Koreans earn much higher than us. We work a day to earn a day's pay. Without work, there is no food. They look down on us, and we don't approve of them.

Many Chaoxian immigrants experience a huge contrast between their expectations and reality. They have suffered both physical and mental hardships in employment and survival, which greatly dampens their self-esteem (Meihua and Yue 2016).

Jiang, who holds an H-2 visa in Ansan City in Gyeonggi-do, describes his and his co-workers' work:

All of us come from Yanbian of Jilin Province, China, and work in the chemical plant here and live in the dormitory provided by the factory. Fortunately, the work here is not demanding, it is all manual work, and we are not capable of doing technical work. Basically, we make a living in the "3D" industries that local Koreans are unwilling to do. Compared to working in our hometown in China, we earn more.

Quan, who holds an H-2 visa, told the author:

I came here more than a decade ago, thinking that in South Korea I could make more money than in China. After I came, I gradually realized that my salary, welfare, and insurance are different from the South Koreans. In a few years, I will return to China when I am old. Since China is developing well now, once we return, we will never come back to be mistreated.

The ordinary Chaoxian immigrant workers in South Korea are engaged in lowlevel work based on physical strength. Their bodies are their means and tools of earning a living. They experience the ups and downs being an imported commodity. "Their bodies as tools are arbitrarily controlled and are often placed in the socially low service sector. They endure extreme physical labor, internal isolation, and experience the ups and downs that are unknown to South Koreans and the embarrassment of being 'the other' at the bottom of society (Meihua 2014)." In addition to low income levels, they endure loneliness and distress after separation from their families, and even suffer discrimination from different classes in South Korea.

The ordinary Chaoxian immigrant workers who are on the fringe of South Korean society can only find satisfaction in constant self-comfort when facing exclusion from the local labor market. In recent years, South Korea's economic 
development has faced many difficulties. It is difficult even for many South Koreans to find a job. The ordinary Chaoxian immigrant workers without high degree of education or professional skills should be more satisfied with such wages. Relative to their income in their hometown, many people think it is worthwhile to work in South Korea.

\section{Knowledge and skills promote deep integration of middle-and-high-end professional groups into south Korean society}

The middle-and-high-end professional groups of Chaoxian immigrants quickly integrated into South Korean society because of their comprehensive qualities such as education level, knowledge, skills and other personal qualifications are much higher than those of the ordinary Chaoxian immigrant workers. Some F-4 visa holders become employees and managers of large South Korean enterprises or engage in personal investment, trade operations, technical guidance and other work. Most F-5 visa holders are mainly engaged in "public occupations" such as education, medical care, public service, journalism, and law.

College students (mainly F-4 visa holders) have higher academic qualifications and can work in large companies in South Korea. They have the opportunity to integrate into South Korean society. Therefore, their social status and income are relatively high (Fang 2013). Compared with the marginalized status of "the ordinary Chaoxian immigrant workers," the Chaoxian immigrant groups of "the large enterprise employees" are accepted by large South Korean companies with high incomes, good working conditions, and good benefits. Nam, who lives in Yeongdeungpo-gu District in Seoul with an F-4 visa, said:

Five years after graduating from university and coming to South Korea, after several years of vocational training and professional examinations, I am currently doing technical work in Hyundai. As far as I know, a few of my classmates who came with me have joined large Korean companies. They work in companies such as Kia, Samsung, LG, and SK, and their living conditions are much better than when they first came.

This group of Chaoxian immigrants also includes private owners who are engaged in catering, construction, commerce, entertainment and processing industries in or around Chaoxian immigrants settlement areas and can obtain considerable economic benefits. Among the interviewees holding F-4 visas in the Chaoxian inhabited areas, there are 21 shopkeepers who have been in business for a long time buying goods from Northeast China, indicating that these Chaoxian immigrants already have strong economic strength. These people are generally business-minded and have a wide range of contacts. They not only interact within the Chaoxian immigrants, but also have extensive contacts with South Koreans. In a large food supermarket in Dalin Dong, Yeongdeungpo District, Kim, a Chaoxian immigrant landlady from Yanbian, Jilin Province, China, has been running a supermarket well for more than 6 years. Kim said: 
Our products are all Chinese products. Now that the supermarket has become large, my husband is busy with the logistics and picking up the goods from our home country, quickly and comprehensively. Sometimes the small shops buy some wholesale from me.

Although the current numbers of F-5 visa holders are relatively small, the number of F-5 visa holders with permanent residence qualifications for the purpose of settlement is increasing (Lanxue 2016). They have a good socio-economic foundation. Although most of them have not become citizens of Korea, they have the intention of staying in South Korea for a long time. In terms of economic integration, these Chaoxian immigrants are working outside the group and accepted by deep integration. Through professional learning, business training, etc., they have improved their working abilities. Like the local Koreans, most of them have higher-level jobs and relatively superior economic conditions, and are able to maintain a decent family life. Some have become elites in South Korean society.

Ms. Zheng, a Chaoxian immigrant from Yanji, Jilin Province, China, holds an F-5 visa and works in a hospital in Seoul. She completed her undergraduate studies in China and her master's and doctoral studies in South Korea. After graduating from Seoul University, Ms. Zheng came to work in this hospital. Due to her diligent study of relevant business knowledge, her level of technological knowledge in the specific business she is now engaged in is already very superb. She feels that this job is suitable for her. Her husband is a Chaoxian immigrant from Heilongjiang Province in China and works in a college in Seoul. The Zhengs have relatively high incomes, and their living standards are no different from those of middle-class South Korean families.

In recent years, most of the Chaoxian immigrants in South Korea like the Zhengs have received good education and are mainly engaged in knowledge-based and technical work. This type of professional population continues to grow. Compared with the early economic conditions when the Chaoxian immigrants first flowed into South Korea, there have been major changes. Those Chaoxian immigrants who can actively integrate into South Korean society often have had higher education in China or South Korea, have worked in related industries for many years, and have strong business capabilities and deeper qualifications. Compared with the previous generations that relied on physical strength, a small number of F-4 visa holders, the vast majority of F-5 visa holders and other middle-and-high-end professional groups have successfully integrated into South Korean economy and many have entered the South Korean elite circle. Their socio-economic status has undergone essential changes.

\section{Closure and interaction: group differences in the social relations integration of Chaoxian immigrants in South Korea}

There is a big group difference between the ordinary Chaoxian immigrant workers and the middle-and-high-end professional groups in terms of social integration. The former is mainly active in the settlement areas and is limited to the social network within the group to form intra-ethnic social interaction, so it is relatively enclosure 
in terms of social integration with South Koreans. However, based on their work characteristics, a small number of F-4 and most F-5 visa holders in the middle-andhigh-end professional groups interact with Koreans through professional contacts and public activities organized by the community outside the immigrant group, and therefore their social interactions are deeper.

\section{Mutual assistance among Chaoxian immigrants has strengthened the closed state of social interactions between the ordinary Chaoxian immigrant workers and south Koreans}

Due to their low income in South Korea, the group of the ordinary Chaoxian immigrant workers often rent small and shabby rooms in the settlements in order to save money. Food and beverages are also very simple, so that they can save money. In terms of social relations, most ordinary immigrant workers tend to use intra-immigrant group, blood, kinship, rural ties, and friendship as the link of social networks, which inevitably further strengthen their intra-immigrant contacts. The strengthening of intra-immigrant communication can provide Chaoxian immigrant workers, especially those Chaoxian immigrants who have just arrived in South Korea with employment information and life assistance, but over time they will lack the initiative to integrate into external social relations. Jin, who lives in a settlement area and holds an H-2 visa, said:

I usually come back from work and chat with the fellow villagers I came with, drink some liquor or beer, play cards, and sometimes go to visit our relatives. On weekends, I go out to climb mountains, sing songs, and we all have fun together. I don't have much chance to contact with South Koreans, and I do not have much to say to them.

Mr. Han holds an F-4 visa and works for a small construction company. He provided some information about social interaction:

I have been working in this construction company for almost 6 years. I usually have very little contact in private with them (South Koreans) except for work matters. I usually do my work well. When I'm not busy, I talk, chat, and get together with my fellow villagers from China. After we get off work, people (South Korean colleagues) live in their own life circle.There is no out of work contact between us.

Some large-scale Chaoxian immigrants associations, service groups, compatriot media, etc., have also formed in the settlement areas. These social organizations have further strengthened their intra--immigration-group relations in the process of helping Chaoxian immigrants solve practical problems such as employment. At present, the largest associations in Seoul are the "Chinese Korean Federation," "Chinese Compatriots One Heart Association," and "The Federation of Chinese Korean Compatriots," etc.. Each organization has more than 5000 members. The "Chinese Korean Federation" organizes various social events about issues that Chaoxian immigrants in South Korea are concerned about, such as computer training, free 
health check-ups, psychological consultation, agency for submission of documents to the Ministry of Justice, non-governmental business cooperation, as well as neighborhood mutual assistance, work-related injury treatment, charities, festival celebrations, etc.. Many service-oriented organizations related to job referrals, vocational training, visa renewal, job training, etc., provide employment assistance for those Chaoxian immigrants when they first arrive in South Korea, as well as for those who need retraining after changing their individual visa type. Through mutual assistance within the Chaoxian immigrants, this "cooperative group feeling" has achieved initial results. However, the closed state of this job group in terms of integration into external social relations is difficult to change. Yoon, a Chaoxian immigrant holding an $\mathrm{H}-2$ visa, has not been in South Korea for a long time and told the author:

I suffered from a cerebral hemorrhage some time ago, and I thought this was over. I couldn't afford the expensive medical care. A friend of mine is a member of the Federation of Chinese Korean Compatriots in South Korea, and he actively called on everyone to donate to pay my medical expenses. I sincerely thank them for helping me escape the jaws of death. I thank that friend and many Chaoxian immigrants for helping me.

A large number of the ordinary Chaoxian immigrant workers living in densely populated areas do not need to establish associations or contacts with local South Koreans because their original relationships with relatives, fellow villagers, neighbors, and friends can satisfy their work, social, and emotional needs. This existing social network, along with various groups and service organizations that provide mutual assistance within the Chaoxian immigrants, has widened the distance between the ordinary Chaoxian immigrant workers and South Koreans in social interaction. Their integration to local social relations has become even more closed. Although this kind of closed state can help them reduce the difficulties they encounter in daily life to a certain extent, but for those Chaoxian immigrants who plan to stay in South Korea for a long time, it is not conducive to comprehensive contact between them and South Koreans. It is impossible to obtain the necessary social resources in the process of integrating into South Korean society through transnational social exchanges.

The closed state of daily communication with South Koreans is commonplace for the ordinary Chaoxian immigrant workers in South Korea. This job group includes H-2 and some F-4, F-2, F-1 and other visa types. The personnel structure is more complicated. Although some of them also interact with South Koreans at work, these mutual assistance interactions are seen more when there is a lack of living resources. There is also class differentiation in South Korean society. South Koreans in low-end service industries are also relatively limited in terms of possession of social resources. When they are employed, they have certain similarities with ordinary Chaoxian workers. This has become an important prerequisite for some ordinary Chaoxian workers to have social interactions with these South Koreans.

Song, 52, is a Chaoxian immigrant from Heilongjiang, China. He came to South Korea with an H-2 visa. He lives in Dalin 1-Dong in Yeongdeungpo District. He has been working here for 12 years. He treats people warmly with a bold personality, likes to make friends, and lives in the same building with several South Korean 
workers as neighbors. They often look for odd work everywhere. If one of them receives an odd job and can't finish it on his own, he will call on each other and do it together. Old Song can now receive odd jobs by himself. Upon receiving a job, Old Song would also call these neighbors. Over the years, they have done odd jobs together in construction, transportation, loading and unloading, expressing delivery, medical care and other part-time work. On days off or when there is no part-time work, they party, drink and chat together, sending each other food. In the eyes of those South Korean workers, Old Song is a generous friend, knowing how to conduct himself in society. They are happy to form a team and do odd jobs with him.

For ordinary workers like Old Song, associating with South Koreans in work and other areas is a method for seeking social resources outside the Chaoxian immigrant group under the condition of extremely limited social resources, striving to establish a social network suitable for their living conditions. Those South Koreans who are engaged in similar low-level jobs also need to seek certain resources in society. This encourages them to form the necessary mutual assistance through certain interactions to better survive. The author also found during fieldwork that, in addition to mutual assistance in work and other links, they will also have dinner and entertainment with South Koreans, trying to break through the small circle of the Chaoxian immigrants and seek a broader communication space. However, this situation still cannot change the closed state of most ordinary Chaoxian immigrant workers in transnational social exchanges.

\section{Career ties and community activities promote deep interaction between middle-and-high-end professional groups and south Koreans}

As mentioned above, the F-4 group among the middle-and-high-end professional groups is mostly working in large enterprises or operating their own businesses, belonging to white-collar workers or private owners. The majorities of the F-5 group are lawyers, teachers, doctors, civil servants, etc., and have high social prestige "public occupations (visible to the public)." Compared with the ordinary Chaoxian immigrant workers, these kinds of professional characteristics allow them to have more opportunities to interact with South Koreans at work.

South Korean employees account for the vast majority in large well-known companies and "public utilities" departments such as the government and hospitals. In modern enterprises, teamwork is part of typical management system or corporate culture in both public and private enterprises. Therefore those Chaoxian immigrants who are engaged in middle-and-high-end occupations have more opportunities for interaction with their South Korean colleagues.

These kinds of social interaction opportunities and social relationship network formed because professional characteristics are the standard of their daily life state and work experience for the middle-to-high-end Chaoxian immigrant group in South Korea. These opportunities are not available to the ordinary Chaoxian immigrant workers.

The author also found in the field work that because some F-5 visa holders have received higher education in South Korea, they can use their academic relationships to interact deeply with South Koreans. This group of people can 
often interact with or help South Koreans in different social and economic fields through classmate relationships, teacher-student relationships, and alumni relationships. For example, Lee (F-5 visa), a 40-year-old Chaoxian immigrant, completed high school in China, and obtained a bachelor's degree and a master's degree at Yonsei University in South Korea. He is currently working in a large company in Seoul. Years of studying in South Korea resulted in him having South Koreans in his classmate circle, and he has a good relationship with some of them. When he was looking for a job or encountered difficulties, his South Korean classmates offered him a lot of help. More Chaoxian immigrants like Lee are receiving higher education in South Korea. These people use the connections they have accumulated during their studies to provide them with more social resources for their survival and development in South Korea.

In addition to daily work, the Chaoxian middle-and-high-end professionals and South Koreans interact with each other through leisure sports, outings, and joint settlement activities in their spare time. Lin, a Chaoxian man holding an F-5 visa, loves life and has wide range of interests. He shares similar hobbies with some South Korean colleagues, and often participates in various outdoor activities with them. He told the author:

I often participate in fitness exercises with them (South Koreans)off work.

Exercise is good for health, and many people know this truth. However, because of being too busy in China, not many office workers really take time to participate in sports.

F-5 visa holders in middle-and-high-end professional groups generally do not live in settlements but live in relatively high-end communities with local South Koreans. Most of them live in areas where South Koreans rent or buy houses. Most of them are neighbors with South Koreans and live in the same community. These people have become registered permanent residents of the local community. This living mode provides a space for the F-5 group and South Koreans to get familiar with each other and know each other well, which also provides an important vehicle for them to integrate into local social relationships. Because they live together in the same "Dong" (street) and the same community, they have an interactive relationship around local public affairs, community services, cultural and sports entertainment, festivals, social welfare and many other matters, which provides the possibility for in-depth understanding of each other.

In interviews, some Chaoxian immigrants with F-5 visas often said such expressions as "we participate in a lot of activities collectively", "all of us often gather together", "community activities are abundant" and "association groups have many activities." A Chaoxian immigrant, with an F-5 visa in Siheung 3-Dong in Geumcheon-gu District (a "mixed" residential area) said enthusiastically:

Living with them (South Koreans), I can participate in various events organized by the "Dong" and the community. The community here does a better job than the domestic communities. Group activities are often arranged on weekends or holidays, and everyone is encouraged to participate. 
Watching concerts, traveling, ball games, festivals, association activities,etc. are very frequent. As long as you are willing, you can participate in activities almost every week. I have participated many times and I have made many South Korean friends.

In the middle-and-high-end professional groups of the Chaoxian immigrants in South Korea, more external exchanges occur and the exchanges are deeper. As far as the F-5 group is concerned, most of them live with South Koreans, and they integrate into local social relations much deeper than the ordinary Chaoxian migrant workers. The social integration of the F-5 group indicates that they have basically adapted to the mainstream society of South Korea. This in turn enhanced their identification with South Korea and accelerated the process of their own cultural adaptation, which is in contrast to the state where the ordinary Chaoxian migrant workers cannot easily integrate into the mainstream society of South Korea.

\section{Heterogeneity and homogeneity: group differences in the cultural integration of the Chaoxian people in South Korea}

\section{The culture and values of life highlight the heterogeneity of the cultural integration of the ordinary Chaoxian migrant workers}

The differences between the Chaoxian immigrants in South Korea and the South Koreans in terms of dress and language are more obvious. Although there are also differences in food, housing, and concepts, they are not as prominent as external characteristics such as dress and accent. Most ordinary Chaoxian migrant workers have low incomes and low living standards, resulting in a difference between their attire and that of most South Koreans. When many of them are dealing with South Koreans, the heterogeneity of dress and external temperament is the first thing to be noticed. Many ordinary workers have to change their clothes, decorations, accents, etc. in order to get better employment opportunities and social resources. They attempt to make changes through "cultural packaging" to make themselves look more like a "South Korean" and reduce their difference in external characteristics with the South Koreans. For example, many young Chaoxian women in South Korea learn to dress up from local South Korean women.

There is a difference between the accent of the Chaoxian immigrants in South Korea and the South Koreans in Seoul and other places. The pronunciation of the Chaoxian immigrants is easily recognized by the local South Koreans, and the identity gap between the two appears immediately. When many Chaoxian migrant workers first arrive in South Korea, their accent will become an identity mark, forming a clear boundary with the South Koreans. In order to adapt to the living environment, the Chaoxian immigrants in South Korea had to imitate South Korean pronunciation and other aspects to minimize the gap in this regard. Chaoxian immigrants's learning and adaptation to Korean accents, clothing, and costumes is an integration 
strategy for passively accepting mainstream culture, which can help them reduce the discrimination they face in making a living in a foreign country.

In the process of adapting to the daily life and culture of South Korea, South Korean fashion culture has created a huge attraction for many young Chaoxian immigrants engaged in ordinary work, and it also shows the heterogeneity of each other's daily life culture. Since the end of 1980s, the South Korean film and television culture, entertainment culture, consumption culture, clothing culture, leisure culture and other fashion culture called "Korean wave" by Chinese media have had an important impact on China's cultural life. Many Chaoxian immigrants, especially young people, are actively migrating to South Korea, largely due to their fascination with South Korean fashion culture. Today, in Chaoxian settlement areas such as Yeongdeungpo District, Guro District, Geumcheon District in Seoul as well as other Chaoxian settlements such as Ansan City and Suwon City of Gyeonggi-do, KTVs, karaoke rooms, theaters, cafes, bars, health centers and other leisure and entertainment venues that have outdated decorations but are still favored by young Chaoxian immigrants can be seen everywhere.

Some entertainment venues in Chaoxian-populated areas provide social space for low-end workers, mainly H-2 groups, to enjoy fashion culture off work. Ms. Park, a 32-year-old Chaoxian immigrant with an H-2 visa, said:

Many of my classmates came to South Korea because they were attracted to South Korean TV series when they were studying in the domestic college. They felt that South Koreans live a fashionable and casual life. After arriving here, we often participate in some local leisure activities on weekends, watch various local entertainment shows, and often buy some fashionable clothes and cosmetics.

In terms of daily life and culture, although there are differences between middle-and-high-end Chaoxian professionals and South Koreans, the heterogeneity is not as obvious as that of the ordinary Chaoxian migrant workers. Many ordinary Chaoxian migrant workers have low academic qualifications, and most of them are engaged in low-end physical work, whose income levels are not high. The gap between the majority of South Koreans and Chaoxian migrant workers in terms of attire and temperament is more significant than that of middle-and-highend professional groups. Many middle-and-high-end professionals have received years of education in South Korea. The Korean pronunciation difference between South Koreans and them is relatively small, so there is no need to deliberately imitate Korean pronunciation in this respect.

The pursuit of South Korean fashion culture also exists in the middle-andhigh-end Chaoxian professional groups, but most of them prefer to engage in elegant leisure and entertainment cultural activities with South Koreans, because their living standards and communication methods are closer to South Koreans. For example, many F-5 visa holders in the middle-and-high-end professional groups like to work out, travel, play golf, or engage in public welfare activities and community affairs with South Koreans in their leisure time; while many ordinary Chaoxian immigrant workers typically spend their evening in small 
groups in chatting and drinking a few bottles of spirits or beer bought from the stalls in front of supermarkets, restaurants, and shops as their main way of leisure.

Owing to different culture and living conditions, most of the Chaoxian immigrant workers differ greatly in values from the South Koreans. In interviews, those low-level manual labor workers mentioned that local people are "inflexible in doing things," "too strong in principle," "too trendy in concept," "utilitarian," "low efficiency," "excessively serious" and other similar expressions. Jin, a Chaoxian immigrant ( $\mathrm{H}-2$ visa) who does odd jobs all year round at construction sites, pointed his finger at the mud on the ground and complained:

This bit of mud mixing is obviously a job that can be done in a day, and the boss (a South Korean) insists that it be done in a day and a half. I am much experienced in the work on the construction site and I can definitely do a good job without quality problems. But it is so stipulated, and you have no choice but to listen to them. If somebody holds your (rice) bowl, someone has to be in charge of you, alas!

These values in the South Korean social context are the rules or working attitudes of South Koreans in daily life practice. Values differences have prompted many ordinary immigrating workers to passively accept the heterogeneous culture of South Korean. In order to avoid unnecessary troubles in daily life, some of them can only passively accept South Korean values in their daily work and social interactions. It is not realistic for the Chaoxian immigrants integrating into the cross-border culture to make their internal value changes in a short time.

Many ordinary Chaoxian immigrant workers have not stayed in South Korea for a long time, and most of them have a "passenger" mentality. During the fieldwork, the author came across Uncle Kim, a (H-2 visa) Chaoxian immigrant who sells vegetables in Dalin Dong, Seoul. He is from Liaoning, China. When the author asked whether he had a long-term plan to make a living in South Korea, he said:

We came here to earn money. It's not easy to work anywhere now. It's a little better to come to South Korea but it's actually not much better. No matter how you get along here, you have to go back sooner or later. There are too many rich people here, no matter how hard we do, we can't afford a house. For us, South Korea will never be our home. I'm looking forward to earning more money and going back. The most important thing is to make my home better.

For Chaoxian immigrants like Kim who engaged in ordinary labor work, they work hard in South Korea only to make a living, not a career. They don't expect to make any achievement in South Korea, but only care about what they achieve in their hometown after earning money (Sung 2016). Most of them did not want to fully integrate into the Korean society after they entered South Korea. Their immigrating purpose was to make money and return to their home country to improve their lives. They showed more passive acceptance of the South Koreans values. 


\section{Religious culture and behavioral styles enhance the homogeneity of cultural integration of middle-and-high-end professional groups}

Christianity, Buddhism, and Shamanism are the three popular religions in South Korea. Christianity has a wide range of believers in Seoul and other places. In South Korea, the Chaoxian middle-to-high-end professional groups have been more in contact with and understand South Korean religious culture and are more proactive in accepting religious beliefs than the ordinary Chaoxian immigrant workers. Their number of believers is also larger.

The similarities in religious beliefs between the middle-and-high-end professionals and most South Koreans have enhanced their homogeneity in cultural integration. Because of the common language and convenient communication, Religious South Koreans are willing to interact and support Chaoxian immigrants who believe in the same religion with them, and even persuade Chaoxian immigrants to believe in a religion. Many Christian organizations in Seoul and other places are also keen to spread Christianity among the Chaoxian immigrants. By giving them material and spiritual help, they attract the Chaoxian immigrants to believe in Christianity. The author learned through fieldwork that very few Chaoxian immigrants believed in religion in China, and most of them did not participate in religious activities. However, when they came to South Korea, the number of Chaoxian immigrants who actively accepted local religious beliefs, especially those middle-to-high-end professionals, are increasing significantly.

Some Chaoxian immigrants having middle-and-high-end occupations actively believe in local religions in the process of integrating into South Korean society. This is not only a result of being influenced by South Korean religious culture, but also a means of integrating into mainstream society through religious beliefs. Through religion, a special element of social relations, they can form a circle of internal communication with South Korean religious believers, which helps them integrate deeply in South Korea. Religious beliefs has been an important part of the spiritual life of many middle-and-high-end professionals, and there are also deeper reasons for they become religious believers. Most of them are mainly engaged in knowledge-intensive occupations, and the competition in their daily work is extremely fierce. For them, both occupational risks and work stress are much greater than those of the ordinary Chaoxian immigrant workers, who are mainly engaged in manual work. Religious belief not only serves as a way for them to relieve their mental stress, but also as an important medium for them to engage in professional contacts and community activities with the upper-middle class of South Korea who believe in the same religion. Nan, a Chaoxian immigrant holding an F-5 visa at Doksan 1-Dong in Geumcheon-gu District in Seoul said:

There are so many Christians here in South Korea, and many of my colleagues often participate in church activities. After being introduced by a close colleague, I also go to the (Christian) church very close to my work unit. I often participate in Eucharist gatherings and have made many South 
Korean friends. After a long time, I gradually begin to believe in Christianity and my mental state has changed. Not only have we met many church members, but our mental stress has also been reduced.

The Chaoxian middle-to-high-end professionals in South Korea are relatively similar to most South Koreans in terms of education, related occupations, living standards, and social relations. Some of them have stayed in South Korea for a long period of time and have deep contact with the upper and middle classes of South Korean society. These specific living conditions make them behave relatively homogeneously with most South Koreans. Shin, a Chaoxian immigrant who lives in Siheung 2-Dong in Geumcheon-gu District, Seoul and holds an F-5 visa, said:

I have been a professor at Chung-Ang University for almost 8 years, and the Korean colleagues around me do everything in the same way: serious, disciplined, and principled. Work can be done well when we follow the regulations, rather than using backdoor relationships. Somethings could have been simplified, but you have to do what is stipulated unless the requirements are revised. When I first came, I was not used to this, and gradually, I got used to it. Now I agree with this behavior rule.

Zheng, a Chaoxian man living in Garibong-Dong, Guro-gu District, Seoul and holding an F-4 visa, opened a money exchange agency by himself to engage in the money exchange business. He said:

I had a relative working in the factory here. He had to complete the factory dormitory procedures within a specified time. It should have been very simple and quick to go through the dormitory check-in procedures, but he spent a long time to complete for the dormitory attendant explained everything in details as if he were a little boy.

His relative (H-2 visa) is very averse to this practice and think it is a waste of time, but Zheng has been in South Korea for so long that he thinks it is not strange for South Koreans to do this.

The behavior way is the internal customary rule of conduct within the society. When integrating culturally into South Korean society, they experience differences in daily life such as food, clothing, and residence. It often takes a long time for the mainstream culture groups to change the behavior of the non-mainstream culture groups, which is basically impossible to achieve in a short time. Because of their short stay in South Korea and different living conditions from South Koreans, it is difficult for ordinary migrating workers like Zheng's relative to accept South Korean behaviors in a short time.

The occupational differences between the ordinary Chaoxian immigrant workers and most South Koreans are large, and there is less interaction between them, so the cultural heterogeneous factors are more prominent. They are relatively weak in cultural integration and can only passively accept the influence of mainstream South Korean culture. The middle-and-high-end Chaoxian professionals and the middle-and-upper-class South Koreans are engaged in similar 
occupations, and their living standards and social status are relatively close so the cultural homogeneity in their social integration is more obvious. In terms of cultural integration, they gain certain advantages over the ordinary Chaoxian immigrant workers, which is mainly reflected in their selective adaptation to the mainstream South Korean culture.

\section{Conclusion}

The income level of middle-and-high-end Chaoxian professionals is not much different from that of the upper-and-middle classes of South Korean, and their completed integration into South Korean economic life makes them different from the ordinary Chaoxian immigrant workers in terms of lifestyle, manners, and views of daily life, dress and acceptance of South Korean norms. They are the ones who are truly integrated into the mainstream South Korean society. Compared with the relatively small number of middle-and-high-end Chaoxian professionals, the ordinary Chaoxian migrant workers have difficulties in integrating deeply into culture, mainstream economy and social relations of South Korea. Though the social integration of middle-and-high-end Chaoxian professional groups is better than that of the ordinary Chaoxian migrant workers, it is clear that the latter group consists the majority of Chaoxian immigrants in South Korea and to a certain extent, the latter reflects the overall integration of the Chaoxian immigrants in South Korea.

The types of visas and occupational differentiation involved in the two major occupational groups of the Chaoxian immigrants in South Korea are complicated, and the social integration of employees holding different visas still overlap at some degree. Although there are obvious differences in the social integration of these two major occupational groups at the economic, social relations, and cultural levels, it does not mean that the social integration between these two groups is completely opposite. In fact, a small number of the ordinary Chaoxian migrant workers have actively integrated into South Korean society, and a small number of middle-and-high-end professional groups have difficulty in integrating into South Korean society. Their social integration is closely related to the life situation, social practice, and psychological cognition of the internal members of certain occupational groups. Occupational type is an important factor but not the only factor that influences differences in social integration. When discussing the issue of group differentiation in the Chaoxian immigrants' integration in South Korean society, the integration differences of different occupational groups should not be viewed mechanically. The social integration of the Chaoxian immigrants is contextual and practical, and the lack of classification or the uses of mechanical classification in research are both unscientific.

The majority of Chaoxian immigrants, upon integrating into South Korea did not achieve the perfect social and cultural integration explained by "peaceful cross-border-living." Similarities in history, culture, language, etc. can reduce some of the obstacles to their integration into the society but cannot solve the real problems they 
encounter when integrating into South Korean society. Looking at the results of such research in the past, most of the Chaoxian immigrants in South Korea are regarded as a whole, ignoring their internal differentiation and differences in integration status. Only by digging out the differentiation and differences in the integration of the Chaoxian immigrants in South Korea can we better understand their true situation when they integrate in South Korea, and adopt more realistic and targeted support and assistance.

In the process of integrating into South Korean society, the majority of the Chaoxian immigrants face the difficulties of marginalization at the economic level, relatively closed social interactions, and passive acceptance in cultural integration. Relevant government departments in China should strengthen publicity and education to allow Chaoxian immigrants to view cross-border flow rationally and to be more diversified in their choice of immigration location. Chaoxian immigrants to South Korea should be helped with vocational skills training before going abroad to enhance their ability to integrate into South Korean society. With the joint efforts of the governments of China and South Korea, the Chaoxian immigrants can have a better space to develop both in China and South Korea and can play a full and special role in maintaining the relations between China and South Korea, and even the social stability of Southeast Asia.

Acknowledgements In terms of fieldwork and document collection, this article has received great help from Dr. Nanri of Chung-Ang University in South Korea. The author would thank the editors and the reviewers for their constructive suggestions and feedback.

Authors' contributions Weihua Ma: Overall research design; Writing original draft: Revising and editing: Ji Chen: Data collection of field work. The authors read and approved the final manuscript.

Authors' information Ma Weihua is a professor in the Department of Sociology, Zhou Enlai School of Government, Nankai University. His primary area of research is urban anthropology. He also focuses on ethnic issues in cities of China. e-mail: ma-wh@126.com

Chen Ji is a professor in the Department of Political Science, Zhou Enlai School of Government, Nankai University. His primary area of research is ethnic sociology. e-mail: nkchenji@126.com

Funding This study is supported by the 2016-2017 International Academic Exchange Funding Project of the Korea Higher Education Foundation "Survey and Research on the Social Adaptation and Employment of Chaoxian people in South Korea", and the 2018 Nankai University Asian Studies Center Funded Project "An Innovative Research on Communications and Exchanges and Integration of Various Ethnic Groups in the Beijing-Tianjin-Hebei Region, and on Government's Collaborative Governance" (Project Number: AS1803).

Availability of data and materials All data generated or analyzed during this study are included in this published article.

\section{Declarations}

Ethics approval and consent to participate Not applicable.

Consent for publication Not applicable.

Competing interests The authors declare no potential conflicts of interest. 
Open Access This article is licensed under a Creative Commons Attribution 4.0 International License, which permits use, sharing, adaptation, distribution and reproduction in any medium or format, as long as you give appropriate credit to the original author(s) and the source, provide a link to the Creative Commons licence, and indicate if changes were made. The images or other third party material in this article are included in the article's Creative Commons licence, unless indicated otherwise in a credit line to the material. If material is not included in the article's Creative Commons licence and your intended use is not permitted by statutory regulation or exceeds the permitted use, you will need to obtain permission directly from the copyright holder. To view a copy of this licence, visit http://creativecommons.org/ licenses/by/4.0/.

\section{References}

Berry, J.W. 1997. Immigration, acculturation, and adaptation. Applied Psychology 46: 5-34.

Berry, J.W. 2002. Cross-cultural psychology: Research and applications. Cambridge: Cambridge University press.

Berry, J.W. 2005. Acculturation: Living Successfully in Two Cultures. International Journal of Intercultural Relations 29: 697-712.

Chengwen, C (陈成文), and S. Jiayue (孙嘉悦). 2012. Social Integration: The Sociological Meaning of a Concept (㖣会融入:一个概念的社会学意义). Hunan Normal University: Journal of Social Sciences (《湖南师范大学社会科学学报》) 6: 66-71.

ChunZi, J (金春子), and W. Jianmin (王建民). 1984, Cross border ethnicities in China (《中国的跨界 民族》). Beijing: The Ethnic Publishing House.

Fang, X (徐芳). 2013. Research on the Social Adaptation of the Floating Population of the Korean Ethnic Group in China (中国朝鲜族流动人口社会适应㸴究), Ph.D. thesis from Central National University (中央民族大学博士论文).

Jeong-Eun, L. (이정은). 2018. Recognition Struggle of Chinese-Korean and Reproduction of Discrimination in South Korea (재한 중국동포의 인정투쟁과 차별의 재생산). Journal of DIASPORA Studies (《디아 스포라 연구》) 1: 145-173.

Chen Ji (陈纪), and Nanri (南日). 2018. Cultural Orientation and Occupation Type: The Differentiation of Chinese Korean Ethnic Identity in South Korea (文化取向与职业类型:在韩中国朝鲜族跨国 族群认同的分化). Journal of Southwest University for Nationalities (《西南民族大学学报》) 7: 40-46.

Jianxin, Z (周建新). 2008. Analysis of the Cultural Model of 'Peaceful Crossing-Living' of Transnational Peoples in Southeast Asia (大陆东南亚跨国民族“和平跨居”文化模式分析). Social Science Front (《社会科学战线》) 8: 183-191.

Lanxue, S (申兰雪). 2016. Influence of Chinese Koreans in South Korea on Local Society (在韩中国朝 鲜族对当地社会的影响), Ph.D. thesis from Yanbian University (延边大学博士论文).

Manli, M (马曼丽). 1995. The Study of Central Asia - A Volume of Transnational Peoples of Central Asia and China. (中亚硎究一中亚与中国同源跨国民族卷). Beijing: National Press (民族出版社).

Meihua, L. (李梅花). 2014. A Journey of Imagination and Reality: A Symbolic Border of Cross-Border Experience and Flow of Chinese Koreans in South Korea.(想象与真实之旅:在韩朝鲜族的跨国体 验和流动的象征边界). Heilongjiang Ethnic Series(《黑龙江民族丛刊》) 6: 34-38.

Li Meihua (李梅花), and G. Yue (郭跃). 2016. Social Adaptation and Obstacles for Chinese Yanbian Korean immigrant workers in South Korea (在韩延边朝鲜族务工群体的社会适应及其障碍因 素). Dongjiang Academic Journal (《东疆学刊》) 1: 43-48.

$\mathrm{Mu}-S e o n, \mathrm{~L}$ (이무 선). 2017. An Empirical Study on Multi-Cultural Family's Housing Satisfaction: With focus on Korean-Chinese in Ansan City (다 문화 가 족의 주거만 족도에 관한 실 증연구:안 산 시 중 국동포를 중 심으로). Korea Academia-Industrial cooperation Society (《한국 산 학 기술 학 회 논문 지》) 10:323-335.

Seung-Yeon, H. (황 승 연). 1994. Adaptation of Korean Chinese to Korean Society (중 국 동 포들의 한 국 사 회 적응 실태 조 사 연구). Journal of Asia-Pacific studies (《아 태연구》) 1:183-208.

Sung, P.K. (朴光星). 2016. Transnational Workers-The Linker of 'Center and Periphery (“跨国打工 者”一经济全球化时代“中心与边缘”的联结者). Journal of Minzu University of China (《中央 民族大学学报》) 1:22-28. 


\section{Comments}

Publisher's Note Springer Nature remains neutral with regard to jurisdictional claims in published maps and institutional affiliations. 